\title{
Challenges and Needs of National Swimming Federations in the Promotion of Health
}

\author{
Clarence Perez-Diaz ${ }^{1}$, Juan Carlos De la Cruz-Marquez ${ }^{1}$, Nuria Rico-Castro ${ }^{2}$ and Belén Cueto-Martín ${ }^{1}$ \\ 1. Department of Physical Education and Sport, Faculty of Sport Science, University of Granada, Granada 18071, Spain \\ 2. Department of Statistics and Operations Research, Faculty of Science, University of Granada, Granada 18071, Spain
}

\begin{abstract}
This study focuses on the current challenges faced by the National Swimming Federations (NFs) with respect to challenges and needs of their NFs in the promotion of health in their domestic population and elite athletes. A descriptive transversal survey was circulated among the FINA NFs requesting information regarding these challenges and needs. The response rate was $64.9 \%$ (135 of the $208 \mathrm{NFs}$ ). A similarity study was conducted (pairing measures method of Rogers-Tanimoto) to obtain 8 groups of NFs organized according to the degree to which their responses were similar to those of the other NFs. The lack of financial resources (95\%) was identified as the most significant barrier to health promotion among the NFs. The least common challenges faced by the NFs were the relative importance of swimming as a sport (52\%) and the lack of evidence based and best practice guidelines (51\%). Conclusion: Although many NFs face some common barriers to promoting health, those barriers are more significant in some NFs. Therefore, the means to overcome them will vary from NF to NF.
\end{abstract}

Key words: Barriers, sport organizations, swimming, development.

\section{Introduction}

Swimming is both a popular and global sport. Swimming is one of only three sports that have "Group A" status at the Olympic Games in recognition of its global appeal [1]. It is widely practiced among both elite and recreational athletes. At the elite level, the number of athletes competing internationally is significant; over 2,400 athletes from 190 nations participated in the 2015 FINA World Aquatics Championships in Kazan [2]. The International Swimming Federation (FINA), and National Swimming Federations ("NFs") organize a high number of athletes and have a duty to protect their health [3]. At the same time, they have an opportunity to leverage the health benefits of their sport to improve public health [4]. However, the task of promoting health through sport is challenging and many barriers are encountered [5]. The extent to which such challenges and barriers apply to sport

Corresponding author: Clarence Perez-Diaz, Ph.D., research field: health promotion in sport federations. organizations was explored by the International Sport Medicine Federation (FIMS), in connection with its research on the importance of medicine within International Sports Federations ("IFs") [6]. The FIMS study identified the specific challenges that an IF may face in this regard. These barriers include: the lack of evidence base and best practice guidelines, the lack of financial resources, the lack of manpower and time, the lack of consideration and recognition on behalf of the decision makers. Our study questions the extent to which NFs encounter these barriers at a national level in the specific sport of swimming.

Swimming is not accessible across all NFs in the same way; NFs will have different challenges depending on their geographical, socio economic situation [7]. For example, intellectual resources might be lower depending in the available medical staff of the NFs. Diop and Miller [8] reported that NFs in developing countries have struggled in relation to sports medicine because they have been driven by volunteers with a minimum administrative support within the organization. Our study will examine 
whether these lack of resources (financial and intellectual) impact upon an NF's capacity to promote health.

Until now, the barriers and challenges faced by the NFs was an area of which little was known. The aim of the study is to bridge this knowledge gap by examining and identifying the main challenges and needs they have promoting health both among their elite athletes and among the general population in their countries.

\section{Methodology}

\subsection{Participants}

The questionnaire was submitted to the 208 national member federations of FINA. The health representatives or designated person of each NF were invited to participate in a detailed descriptive transversal online survey, assuring the anonymity of the respondents and respecting the applicable regulations of the EU in relation to data protection (the ethical clearance number of the manuscript is UGR. 58CEIH/2014).

An email invitation, including an introduction of the survey and its objectives, as well as instructions for how to access the survey electronically was sent out to each contact person on the 1st of October 2014. The survey was also distributed in person at one occasion (the FINA Aquatics Convention 2015) to all the NFs with identical instructions. The NFs were asked to submit their responses online or on paper (alternative in the two events). If a question was unanswered, it was excluded from the analysis. The first NF submitted their responses in October 2014 and the last in February 2015.

\subsection{Survey}

The survey was designed based on the results of the FIMS research on IFs [9] and was tailored to the specific goals of this study. A pilot study was carried out by two independent experts in the area of Sport Science from the University of Granada through a blind review.
A statistical validity and reliability was obtained (Cronbach $\alpha$ coefficient of 0.8642 for $n=15$ ). The survey was created using the free software platform LimeSurvey (GNU /GPL v2) available at the Center for Computing and Network Services, University of Granada.

The questionnaire was available in English, Spanish, French, and Russian.

NFs were asked to provide responses in relation to the following pre-selected challenges and needs in promoting health: Lack of consideration and recognition on behalf of decision makers, Lack of evidence based and best practice guidelines, Lack of financial resources, Lack of manpower/time, Lack of swimming facilities, Need for more support from the National Olympic Committee (NOC), Continental or International Federation (training, advice, resources), Swimming not being ranked as an important sport in their country.

\subsection{Analysis}

The raw data was exported from the survey tools and analyzed (blind method) by the research team. The questionnaire was built using a blend of dichotomous and five-point Likert scale response alternatives.

A similarity study was carried out using the Roger Tanimoto test. Accordingly, the NFs were classified in eight groups according to the degree to which their responses were similar to those of the other NFs. To obtain the results, the distance between NFs based on the information provided was established. The interlinkage among NFs was determined using the agglomerative hierarchical clustering method in order to categorize the NFs into the 8 groups.

\section{Results}

The overall response rate was $64.9 \%$ (135 of the 208 NFs). $61 \mathrm{NFs}(45.1 \%)$ replied to the questions that 'they do not know' or had 'no comment'. Two answers were given from Canada (Canada Aquatics and Canada swimming). Therefore a total $135 \mathrm{NFs}$ replied but from 
134 countries. The results of Belgium are represented by the Flemish Swimming Federation.

The resulting dendrogram establishes 8 groups (A, B, C, D, E, F, G and H) (Table 1, Figs. 1 and 2).

When considering the results for Groups G, F and H, it must be borne in mind that these four groups account for just fewer than $3 \%$ of the NFs that provided answers to these questions.

In terms of the identification of the challenges within the structure of the federations the most consistent group has been Group B (26 NFs: 35.1\%); it reported to experience challenges in all of the categories. These NFs reported to experience the highest level of challenges to the development of their health objectives $(31.4 \%)$.

\subsection{Lack of Financial Resources}

The most reported challenge among the NFs is the lack of financial resources (95.9\%). The NFs of Group $\mathrm{B}, \mathrm{C}, \mathrm{E}, \mathrm{G}$ and $\mathrm{H}$ NFs identified this issue as their biggest challenge. Significantly, this challenge was most present (35\%) in the largest group, Group B.

\subsection{Lack of Manpower/Time}

The second biggest challenge reported by the NFs is the lack of manpower and time. $86 \%$ of NFs reported this issue as a challenge.

\subsection{Need More Support from the NOC, Continental or}

International Federation (Training, Advice, Resources)

The third main challenge is the need for more support from the NOC, Continental or International Federations. This was more prevalent in Group D (all of the 11 NFs reported this issue) and Group G (both of the $2 \mathrm{NFs}$ reported this issue) compared with the NFs in Groups A, B, C, and E where this challenge was less of an issue.

\subsection{Lack of Swimming Facilities}

The lack of swimming facilities was highly reported among the NFs in Group A (top challenge), Group B, Group D, Group E and Group G, while in Group C, none of the $10 \mathrm{NFs}$ reported that issue as a challenge. This was also the case for the NFs in Group F and E.

Table 1 Barriers and challenges.

\begin{tabular}{|c|c|c|c|c|c|c|c|c|c|c|c|c|c|c|c|c|}
\hline & \multicolumn{2}{|c|}{$\mathrm{B}$} & \multicolumn{2}{|c|}{$\mathrm{E}$} & \multicolumn{2}{|c|}{$\mathrm{D}$} & \multicolumn{2}{|c|}{$\mathrm{C}$} & \multicolumn{2}{|c|}{ A } & \multicolumn{2}{|c|}{$\mathrm{G}$} & \multicolumn{2}{|c|}{$F$} & \multicolumn{2}{|c|}{ TOTAL } \\
\hline & $n$ & $\%$ & $n$ & $\%$ & $n$ & $\%$ & $n$ & $\%$ & $n$ & $\%$ & $n$ & $\%$ & $n$ & $\%$ & $N$ & $\%$ \\
\hline & 26 & 35.1 & 14 & 18.9 & 11 & 14.8 & 10 & 13.5 & 9 & 12.1 & 2 & 2.7 & 1 & 1.3 & 74 & 100 \\
\hline $\begin{array}{l}\text { Lack of financial } \\
\text { resources }\end{array}$ & 26 & 35.1 & 14 & 18.9 & 10 & 13.5 & 10 & 13.5 & 8 & 10.8 & 2 & 2.7 & 1 & 1.3 & 71 & 95.9 \\
\hline $\begin{array}{l}\text { Lack of manpower/ } \\
\text { time }\end{array}$ & 25 & 33.7 & 12 & 16.2 & 10 & 13.5 & 10 & 13.5 & 7 & 9.4 & 0 & 0 & 0 & 0 & 64 & 86.4 \\
\hline $\begin{array}{l}\text { Lack of support from } \\
\text { NOC, CF/IF }\end{array}$ & 22 & 22.9 & 12 & 16.2 & 11 & 14.8 & 9 & 12.1 & 6 & 8.1 & 2 & 2.7 & 0 & 0 & 62 & 83.7 \\
\hline $\begin{array}{l}\text { Lack of swimming } \\
\text { facilities }\end{array}$ & 21 & 28.3 & 13 & 17.5 & 9 & 12.1 & 0 & 0 & 9 & 12.1 & 2 & 2.7 & 0 & 0 & 54 & 72.9 \\
\hline $\begin{array}{l}\text { Lack of consideration/ } \\
\text { recognition from } \\
\text { decision makers }\end{array}$ & 26 & 35.1 & 7 & 3.3 & 0 & 0 & 6 & 8.1 & 1 & 1.3 & 2 & 2.7 & 0 & 0 & 42 & 56.7 \\
\hline $\begin{array}{l}\text { Swimming is not ranked } \\
\text { as an important sport in } \\
\text { our country }\end{array}$ & 17 & 22.9 & 14 & 18.9 & 4 & 5.4 & 3 & 4 & 0 & 0 & 0 & 0 & 1 & 1.3 & 39 & 52.7 \\
\hline $\begin{array}{l}\text { Lack of evidence based } \\
\text { and best practice } \\
\text { guidelines }\end{array}$ & 26 & 35.1 & 0 & 0 & 11 & 14.8 & 0 & 0 & 0 & 0 & 1 & 1.3 & 0 & 0 & 38 & 51.3 \\
\hline & 23.2 & 31.4 & 10.2 & 13 & 7.8 & 10.5 & 5.4 & 7.3 & 4.4 & 5.9 & 1.2 & 1.7 & 0.2 & 0.3 & 52.8 & 71.3 \\
\hline & 3.4 & 4.6 & 5.1 & 7.9 & 4.2 & 5.7 & 4.4 & 6 & 3.9 & 5.3 & 0.9 & 1.2 & 0.5 & 0.6 & 13.3 & 18 \\
\hline
\end{tabular}

* NR: 61 NFs (45.2\%). NOC: National Olympic Committee; CF: Continental Federation. IF: International Federation.

Group H: The 1 NF of Group H reported not having any challenge in any of the indicated issues. 


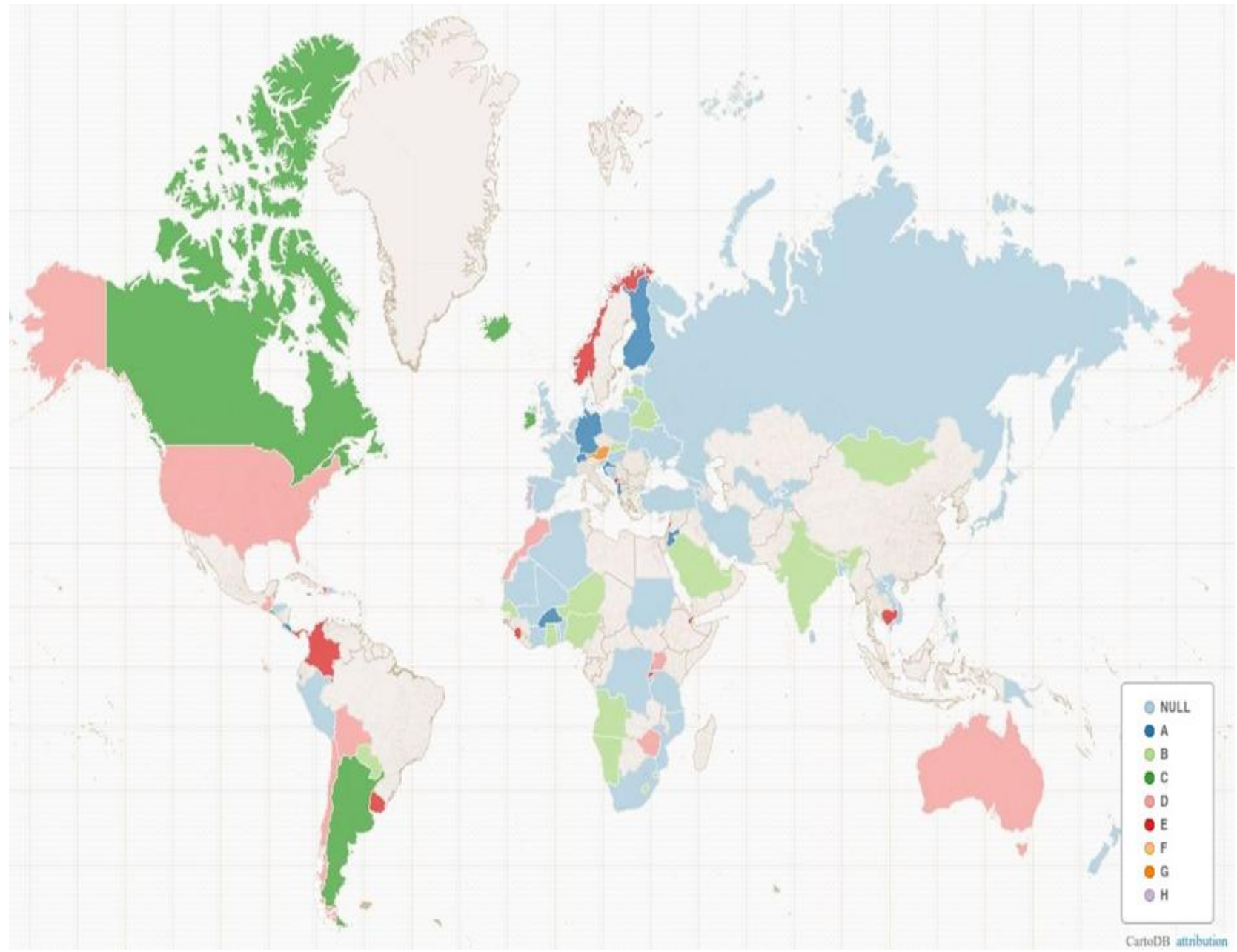

Fig. 1 Map of the world groups representation.

Lack of financial resources

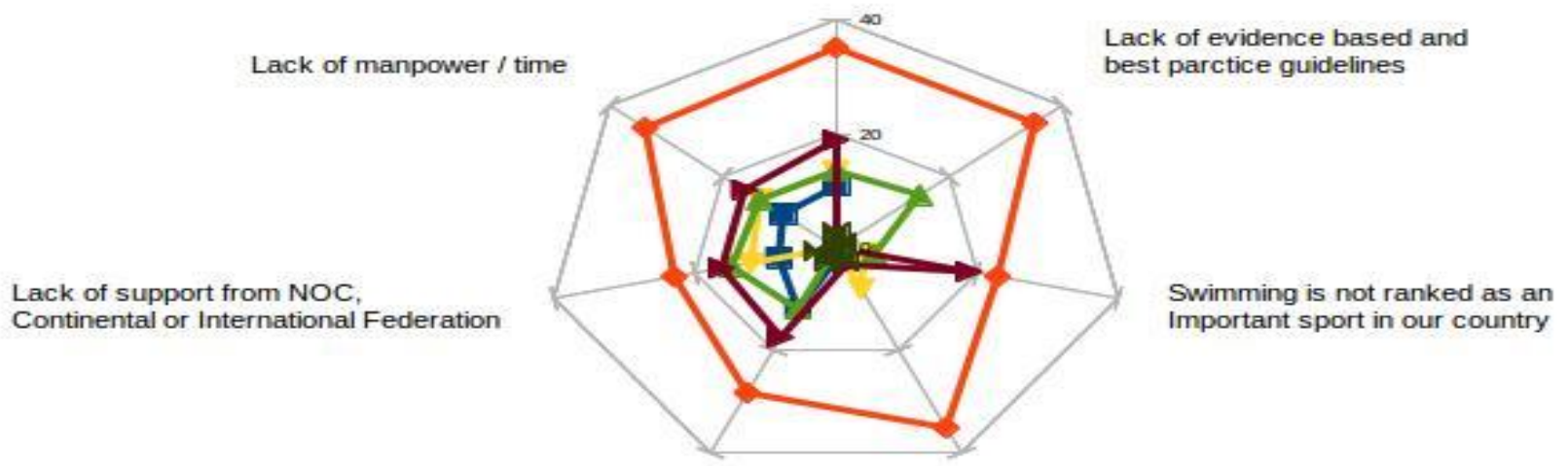

Lack of swimming facilities

Lack of consideration and recognition on behalf of decision makers
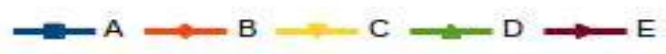

E

Fig. 2 Prevalence of the barriers.

* Kiviatt Chart 1. The prevalence of the barriers has been shown using a counter clockwise starting, with the most common barrier (Lack of Financial Resources) at 12.00 and ending at 13.00 with the least common barrier (Lack of evidence based and best practice guidelines). 


\subsection{Lack of Consideration and Recognition on Behalf of Decision Makers}

Overall the lack of consideration and recognition on behalf of the decision makers was not reported to be a significant issue compared with the others challenges (56\%). Significantly, all of the 26 NFs in Group B reported this as a challenge.

3.6 Swimming Is not Ranked as an Important in Our Country

The challenge of swimming not being ranked or perceived as an important sport in their country was the second lowest ranked challenge faced by the NFs. Overall, 52\% reported this as a challenge, with the highest reporting being among the NFs in Group E (all of the 14 NFs reported this challenge) and Group B (17 of the $26 \mathrm{NFs}$ ).

\subsection{Lack of Evidence Based and Best Practice} Guidelines

Overall the lack of evidence based and best practice guidelines was ranked as the lowest of the suggested challenges (51\%); however, all of the 27 NFs in Groups $\mathrm{B}$ and $\mathrm{D}$ cited this as a challenge that they face.

\section{Discussion}

The NFs were asked to confirm which of the pre-selected challenges they experienced in promoting health.

The NFs of the largest group, Group B, reported to experience significant challenges in relation to health promotion. It was the only group where all of the challenges were experienced by at least some of the NFs.

The 14 NFs of Group E reported to face significant in relation to all the suggested challenges, with the exception of lack of evidence based and best practice guidelines $(0 \%)$.

\subsection{Lack of Financial Resources}

The lack of financial resources was identified as the most significant challenge to health promotion among the NFs. In addition to influencing the NFs' ability to focus on health promotion, it is evident that a lack of financial resources also impacts other areas of their operation, such as the ability to develop needed infrastructure (e.g. swimming facilities) or hire adequate manpower in the NF [10].

Notably many countries that reported this issue were also from "developed countries" (31 NFs from developed countries). The categorization of a NF as a "developed country" is based on the International Statistic Institute who defines developing countries based on their National Gross Income (GIN) per capita and per year [11]. These results are not aligned with previous findings that document that low GDP levels are mainly a difficulty for developing countries, also in the area of sport [12]. Further studies comparing developing and developed NFs in relation to this topic are required.

\subsection{Lack of Manpower and Time}

Diop and Miller reported that developing NFs have struggled in relation to sports medicine because they have been driven by volunteers with a minimum administrative support within the organization [13]. If NFs are serious about moving towards a more professional structure, they need to ensure the quantity and quality of their staff [14]. The result of our study shows that the NFs lack the manpower to achieve this level of professionalization in relation to their medical resources and services.

4.3 Need for More Support from the National Olympic Committee, (NOC) International Federation (IF) or Continental Federation (CF) (Training, Advice and Resources)

The IF [15], the IOC (Olympic Solidarity) [16] and the NOCs through IOC Solidarity support NFs through their development programmes. An example of such support are the scholarship programmes which benefit the health of individual swimmers by providing them with access to appropriate medical staff during their 
whole career [17]. Scholarship recipients could be leveraged and used as ambassadors in order to highlight the benefits of swimming for health in the general population and to deliver certain key messages on this topic, thereby establishing a health promotion legacy. One such example was set by the Tanzanian Olympic team, which was the first to join the African Olympic campaign against malaria [18], showing that it is not always necessary to create new programmes. Instead, the existing programmes can be adapted and expanded. NFs could also be more pro-active by, for example, attending sports medicine courses offered through the International Federation of Sports Medicine (FIMS) network [19].

\subsection{Lack of Swimming Facilities}

$72 \%$ of the NFs reported that the lack of swimming facilities was a challenge. The main exception was the Group C NFs, none of whom reported it as an issue. It is not unusual for some NFs to rely on hotel swimming pools to train their athletes and host coaching workshops [20]. One must also consider that financial resources are not only needed to construct swimming pools, but also to maintain them. This was highlighted in a UN study conducted in Ethiopia, in which it was stated that "building and maintaining sport infrastructure is an ongoing challenge" [21]. On top of this, it has been shown that a swimming pool that is not well maintained could actually be counterproductive in terms of health promotion [22]. Furthermore, the need for surveillance staff linked to prevention of drowning must be considered as an aspect of global drowning prevention [23]. Therefore the challenges of lack of financial resources and lack of manpower and time, both of which were highly reported challenges, could be contributing factors to the prevalence of the issue of lack of swimming facilities.

\subsection{Lack of Consideration and Recognition on Behalf of the Decision Makers}

$56 \%$ of NFs identified the lack of consideration on behalf of the decision makers as a challenge within their NFs. Decision makers are less likely to push for health promotion initiatives if people with expertise in this area are not present at the top table to make a case for this. Sport organizations should include a medical commission within their governance structure for the purpose of emphasizing the importance of sport medicine for athletes and to demonstrate a willingness on the part of sports organizations to prioritize work in this field [24].

\subsection{Relative Importance of Swimming as a Sport}

$52 \%$ of the NFs confirmed that swimming is not considered an important sport in their country. This is to be expected given that football is by far the most popular sport worldwide [25] and the number one sport in most countries leaving other sports, like swimming, to compete for the remaining resources (both human and capital) [26].

Furthermore, swimming has to compete along with other Olympic sports in its country's in order to receive funding and support from their NOCs and IOC Solidarity programmes [27].

\subsection{Lack of Evidence Based and Best Practice Guidelines}

This was the lowest ranked challenge among the NFs. The existence of this issue as a challenge was confirmed by all of the Group B and D NFs. However, the need for more health guidelines or policies is not unique to some not just an issue for national swimming federations. Dobbinson et al. [28] found that the main barriers perceived by Australian sport clubs in terms of health promotion policies were a lack of support from health agencies (training, advice, resources) and sample policies to follow.

Addressing this issue could be a practical way to assist NFs with their health promotion activities, or at least increasing it as it as priority for them. For example, the guidelines developed by the International Sport for All Association to improve health promotion among 
sport clubs set out a practical framework, which could also be employed among NFs [29].

\section{Conclusions}

NFs across the world face certain common challenges to health promotion. The main findings of our study show that these barriers and challenges are not necessarily common across regions or continents.

The many challenges faced by NFs in relation to health promotion cannot be regarded in isolation since many of them are linked. This indicates that a holistic approach to overcoming these challenges is required. The lack of financial resources is the primary challenge for the NFs and is holding them back from actively engaging in health promotion activities.

\subsection{Other Possible Barriers and Perspective for the} Future

It should also be borne in mind that 61 of the 135 NFs replied to the questions that "they do not know" or had "no comment". This can be perhaps due to the fact that the challenges suggested in the survey did not include the specific challenges faced by those NFs. Another factor could have been that NFs were not comfortable drawing attention to problems that they face or that they did not have the resources or information to reply to the question(s).

A further study is required to determine the medical personnel structures within NFs. Given that the majority of the NFs identified the lack of consideration and recognition of health issues on behalf of the decision makers as a challenge, a study focusing on the absence/presence of medical commissions and medical personnel on decision making bodies of NFs would be of particular interest.

It is necessary to emphasize the importance of information sharing amongst National Federations' medical personnel [30]. The NFs have certain commonalities in terms of barriers, challenges and health promotion within their sport and there is a potential for them to exchange certain knowledge, experience and data with the goal of raising the level of health promotion/protection amongst their swimmers. Input from CFs and perhaps also, FINA, would be required in order to structure and facilitate this transfer of knowledge.

\section{Acknowledgements}

The authors highly appreciate the co-operation of the National Swimming Federations and their staff who responded to this survey providing data for this study.

\section{References}

[1] ESPN Internet Ventures. 2013. "Swimming, Gymnastics get Boost." Accessed April 25, 2016. http://espn.go.com/olympics/story/_/id/9321066/swimmi ng-gymnastics-get-olympic-revenue-boost

[2] FINA. 2015. "16th FINA World Championships 2015 in Kazan.” Accessed April 17, 2016. http://kazan2015.com/en/news_items/3667

[3] FINA Medical Rules. 2008. Chapter II: Protection and Promotion of the Athletes Health during Training and Competition. In FINA Medical Rules Lausanne. Ed. FINA, 1-7.

[4] Hardman, A., and Stensel, D. 2003. Physical Activity and Health: The Evidence Explained. London: Routledge.

[5] Sport for Development and Peace International Working Group (SDP IWG). 2008. "Harnessing the Power of Sport for Development and Peace: Recommendations to Governments. Chapter 2 Sport and Health." Accessed April 25, 2016 http://www.un.org/wcm/webdav/site/sport/shared/sport/S DP\%20IWG/Chapter2_SportandHealth.pdf

[6] FIMS Interfederal Commission. 2015. "Survey on the Importance of Medicine in International Sports Federations." Accessed February 26, 2016 http://www.fims.org/files/3914/2063/3554/IFC-Survey-R esults-2011.pdf

[7] Amusa, L. O., Toriola, A. L., Onyewadume, I. U., and Dhaliwal, H. S. 2008. "Perceived Barriers to Sport and Recreation Participation in Botswana." African Journal for Physical, Health Education, Recreation and Dance 14 (2): 115-29.

[8] Diop, M., and Miller, J. 2011. "Sport Medicine in Our National Federations: The Case of Developing Countries." FINA Aquatics World magazine 2011 (2): 100-1.

[9] FIMS Interfederal Commission. 2015. "Survey on the Importance of Medicine in International Sports Federations." Accessed February 26, 2016. http://www.fims.org/files/3914/2063/3554/IFC-Survey-R 
esults-2011.pdf

[10] United Nations. 2016. "Government in Action Part III-National Overviews E-P" The United Nations. Accessed $\quad$ February 23, 2016. http://www.un.org/wcm/webdav/site/sport/shared/sport/p $\mathrm{dfs} / \mathrm{SDP} \%$ 20IWG/Governments\%20in\%20Action\%20Par t\%20III\%20-\%20National\%20Overviews\%20E-P.pdf

[11] The International Statistical Institute. 2015. "List of Developing Countries." Accessed June 29, 2015. http://www.isi-web.org/index.php/resources/developing-c ountries

[12] Andreff, W. 2008. "Globalization of the Sports Economy." Rivista di Diritto ed Economia dello Sport 4 (3): 107-12.

[13] Diop, M., and Miller, J. 2011. "Sport Medicine in Our National Federations: The Case of Developing Countries." FINA Aquatics World magazine 2011 (2): 100-1.

[14] Siegfrieda, N., Schlesingerb, T., Baylec, E., and Giauqued, D. 2015. "Professionalisation of Sport Federations - a Multi-Level Framework for Analysing Forms, Causes and Consequences." European Sport Management Quarterly 15 (4): 407-33.

[15] FINA. 2010. "Building New Ways for Success in Aquatic Sports." In FINA National Federations Development Handbook 2010. London: Gee Publishing, 1-384.

[16] Olympic Solidarity. 2013 Annual Report. London: Gee Publishing, 41-52.

[17] Olympic Solidarity. World Programmes Athletes. 2016. “Olympic Scholarships for Athletes RIO 2016.” Accessed April 25, 2016. http://www.okbih.ba/pdf/world_programmes/A\%20-\%20 Athletes/2\%20-\%20Olympic\%20Scholarships $\% 20$ for $\% 2$ 0Athletes\%20-\%20Rio\%202016/2.1\%

[18] Sow, A. 2008. "Importance and Role of the Athlete in the Control of Major Communicable Epidemics in Africa: The Case of Malaria." In Health and Sports in Africa Challenge for Development, edited by François-Xavier, M. K. Dakar: Editions John Libbey Eurotext.

[19] FIMS. 2016. "FIMS Courses." Accessed April 25, 2016. http://www.fims.org/news-events/fims-courses/

[20] FINA News. 2015. "FINA Reaches Out to the World with More Development Programmes in 2015. Successful FINA Swimming Clinic for Coaches in St Kitts \& Nevis." Accessed March $\quad 18,2016$. http://www.fina.org/news/fina-reaches-out-world-more-d evelopment-programmes-2015

[21] United Nations. 2008. "Sport for development and peace: Governments in action Part III-National Overviews E-P-the United Nations". Accessed February 23, 2016. http://www.un.org/wcm/webdav/site/sport/shared/sport/p dfs/SDP\%20IWG/Governments\%20in\%20Action\%20Par t\%20III\%20-\%20National\%20Overviews\%20E-P.pdf

[22] World Health Organization. Water, Sanitation and Health Team. 2006. Guidelines for Safe Recreational Water Environments. Volume 2 Swimming Pools and Similar Environments. Geneva: World Health Organization, 12-22.

[23] Van Beeck, E. F., Branche, C. M., Szpilman, D., Modell, J. H., and Bierens, J. J. L. M. 2005. "A New Definition of Drowning: Towards Documentation and Prevention of a Global Public Health Problem." Bulletin World Health Organization 83 (11): 853-6.

[24] Engebretsen, L., and Steffen, K. 2015. "Protection of the Elite Athlete Is the Responsibility of All of Us Sports Medicine." British Journal of Sports Medicine 49 (17): 1089-90.

[25] D'Hooghe, P. 2013. "Football-The People's Game." Aspetar Sports Medicine Journal 2 (Targeted topic-Sports Medicine in Football), 206-10.

[26] Andreff, W. 2006. Handbook on the Economics of Sport/Wladimir Andreff, Stefan Szymanski. Cornwall (Great Britain): MPG Books Ltd., 1-830.

[27] IOC Olympic Solidarity Commission. 2013. Annual Report. A Direct Line! London: Gee Publishing, 1-68.

[28] Dobbinson, S. J., Hayman, J. A., and Livingston, P. M. 2006. "Prevalence of Health Promotion Policies in Sports Clubs in Victoria, Australia." Health Promotion International 21 (2): 121-9.

[29] The Association for International Sport for All. 2009. The Guidelines for Sports Club for Health (SCforH) Programs. The Report. Helsinki.

[30] McCall, A., Davison, M., Andersen, T. E., Beasley, I., Bizzini, M., Dupont, G., and Dvorak, J. 2015. "Injury Prevention Strategies at the FIFA 2014 World Cup: Perceptions and Practices of the Physicians from the 32 Participating National Teams." British Journal of Sports Medicine 49 (9): 603-60. 